\title{
Elevating local knowledge through participatory modeling: active community engagement in restoration planning in coastal Louisiana
}

\author{
Scott A. Hemmerling ${ }^{1}$ (D) $\cdot$ Monica Barra ${ }^{2} \cdot$ Harris C. Bienn ${ }^{1}$. \\ Melissa M. Baustian ${ }^{1} \cdot$ Hoonshin Jung ${ }^{1} \cdot$ Ehab Meselhe $^{3} \cdot$ Yushi Wang $^{1}$. \\ Eric White ${ }^{1}$
}

Received: 18 February 2019 / Accepted: 18 September 2019 / Published online: 5 October 2019

(c) The Author(s) 2019

\begin{abstract}
Numerical modeling efforts in support of restoration and protection activities in coastal Louisiana have traditionally been conducted externally to any stakeholder engagement processes. This separation has resulted in planning- and project-level models built solely on technical observation and analysis of natural processes. Despite its scientific rigor, this process often fails to account for the knowledge, values, and experiences of local stakeholders that often contextualizes a modeled system. To bridge this gap, a team of natural and social scientists worked directly with local residents and resource users to develop a participatory modeling approach to collect and utilize local knowledge about the Breton Sound Estuary in southeast Louisiana, USA. Knowledge capture was facilitated through application of a local knowledge mapping methodology designed to catalog local understanding of current and historical conditions within the estuary and identify desired ecological and hydrologic end states. The results of the mapping endeavor informed modeling activities designed to assess the applicability of the identified restoration solutions. This effort was aimed at increasing stakeholder buy-in surrounding the utility of numerical models for planning and designing coastal protection and restoration projects and included an ancillary outcome aimed at elevating stakeholder empowerment regarding the design of nature-based restoration solutions and modeling scenarios. This intersection of traditional science and modeling activities with the collection and analysis of traditional ecological knowledge proved useful in elevating the confidence that community members had in modeled restoration outcomes.
\end{abstract}

Keywords Participatory modeling · Competency group · Natural and nature-based solutions · Traditional ecological knowledge $\cdot$ Coastal Louisiana

Scott A. Hemmerling

shemmerling@thewaterinstitute.org

Extended author information available on the last page of the article 


\section{JEL Classification Y800}

\section{Introduction}

Coastal Louisiana has experienced a globally high rate of wetland loss due in part to a combination of sea level rise, subsidence, saltwater intrusion, and reduced sediment inflow (Barras et al. 2003; Blum and Roberts 2009; Day et al. 2000, 2011; Scavia et al. 2002; Turner 1997). Between 1932 and 2016, coastal Louisiana lost approximately 4833 square kilometers of wetlands and is predicted to lose an additional 5827 square kilometers over the next 50 years (Couvillion et al. 2017; Louisiana Coastal Protection and Restoration Authority 2017). The loss of these coastal wetlands represents not only a deterioration of ecological and economic viability, but a loss of the vital shoreline protection zone that insulates coastal communities from the impacts of coastal hazards such as storms and the effects of climate change (Laska et al. 2005). As more wetlands are lost, coastal communities will become increasingly vulnerable to storm surge, coastal flooding, and tropical weather events. The region is home to a wide range of ethnic and cultural groups that have long coped with extreme weather events, enhancing community resilience through strong family, ethnic, and religious ties (Colten et al. 2018). A number of these ethnic and social groups, including Native American, Acadian, Isleño, African American, and Vietnamese, which reside in the coastal parishes are often supported by livelihoods based on the abundant renewable and nonrenewable natural resources of the region. Residents residing in this changing environment will be forced to either adapt or relocate away from the coast. Those who choose to remain, or who lack the means to relocate, may face increasing economic threats in addition to environmental threats, as rising insurance rates may make living in coastal areas unaffordable (Dalbom et al. 2014).

Much of Louisiana's coastal zone is outside of the current system of hard or gray infrastructure (primarily levee) protection. Therefore, the potential benefits of protecting, restoring, and enhancing intact ecosystems via green infrastructure-including the potential benefits to humans in terms of protection from waves and storm surge as well as provision of fisheries and livelihoods - are particularly important to these most vulnerable communities (Carruthers et al. 2017). Maintenance and restoration of intact coastal ecosystems are globally considered to have high potential for supporting community resilience (Travers et al. 2012), which can also be applied to coastal communities of Louisiana. Natural solutions are those conserving existing habitats such as salt marshes while nature-based solutions are those created by humans, such as oyster reefs (Arkema et al. 2017). The ecosystem functions of these solutions provide essential ecosystem services that can increase community resilience through: reducing direct impacts of waves, storm surges, and marginal erosion; provision of essential habitat for juvenile and adult fisheries species, ducks, and other hunted species; and potential revenue raising functions such as nutrient and carbon sequestration (Barbier et al. 2011; Chesney et al. 2000; Gedan et al. 2011; Mitsch and Gosselink 1986). The 2017 Louisiana's Coastal Master Plan for a Sustainable Coast focuses both on structural or engineered protection and restoration 
(Louisiana Coastal Protection and Restoration Authority 2017). Natural and naturebased solutions that can restore or enhance intact natural ecosystems such as barrier islands, marshes, mangrove stands, aquatic vegetation, and forested wetlands are an important component of restoration efforts (Boesch 2006; Boesch et al. 1994). These solutions also provide additional nonstructural protection from flooding or surge attenuation that have the potential to enhance community resilience in some of the most vulnerable parishes that are not amenable to structural protection options (Dalbom et al. 2014).

Alongside their anticipated benefits, many of these protection and restoration projects are also projected to disrupt ecological conditions that sustain the coastal resources that many of Louisiana's residents rely on for their livelihoods and sustenance (Colten et al. 2018). When these impacts are inadequately planned for, knowledge controversies may develop, leading to conflict between residents and public officials. In coastal Louisiana, one such knowledge controversy has developed around the planned reintroduction of Mississippi River water and sediment into the Breton Sound Estuary in an attempt to mimic the natural functioning of the river delta (Barra 2016). Public opposition to this and other large-scale sediment diversion projects has developed around a number of perceived threats, including the over-freshening of coastal estuaries, displacement of fisheries, and the assertion that nutrients in the river water will lead to degraded water quality (Bargu et al. 2019) and wetland deterioration (Day et al. 2018). Despite recent efforts by public officials and scientists to actively engage with coastal residents and stakeholders, many of these residents still feel that their local knowledge is not ultimately accounted for in the coastal restoration planning process within their own communities, eroding public trust in both scientists and public officials (Carruthers et al. 2017; Hemmerling et al. 2019). This gap between practice and perception highlights the need for new, meaningful, and actionable ways of accounting for and integrating stakeholder input into the environmental planning and decision-making process.

Several recent advances in geospatial technologies allow for the input of qualitative local knowledge into mathematical models and have provided tangible ways to evaluate quantitatively the potential outcomes of restoration and protection projects, which can allow coastal planners to better respond to the short- and long-term needs of impacted communities. The results from these approaches can provide a new, geographically targeted evidence base for planning strategies, especially those focused on mitigation and recovery (Curtis et al. 2018). Local knowledge mapping (LKM) is one such approach that aims to encourage community members to share knowledge and perceptions of a given area and has been shown to provide an effective means of incorporating community and traditional ecological knowledge (TEK) into a coastal protection and restoration framework. Qualitative data collected during LKM exercises have been used to create geospatially explicit baseline datasets allowing researchers to incorporate local knowledge into an assessment of ecological restoration projects (Barra 2017; Carruthers et al. 2017). When incorporated into a GIS environment and assessed in combination with biophysical data, the resultant "Sci-TEK" data can potentially be used to refine the large conceptual footprints of restoration projects and aid in the identification of future restoration projects, and identify associated areas of consensus and potential conflict between 
local stakeholders and policymakers (Bethel et al. 2011, 2014, 2015). The incorporation of these data into the planning process would represent an important step in identifying and reducing the risk of disproportionate impacts on particular social or cultural groups.

While the goal of LKM, Sci-TEK, and other geospatial techniques is to translate local knowledge into model-ready frameworks, and the stakeholder engagement techniques used during qualitative data collection need to directly elicit a sense of ownership and trust in the process itself. Effective engagement should be an ongoing process that fosters social learning among stakeholders and provides a means of arriving at consensus among a large group of stakeholders. Methods such as participatory integrated planning (Castelletti and Soncinisessa 2006) and deliberative multicriteria evaluation (Mavrommati et al. 2017) encourage two-way knowledge building and active involvement of impacted stakeholders in the analysis of environmental problems and design of potential solutions. A competency group approach takes these principles of active involvement of stakeholders one step further and challenges assumptions about the fundamental differences between scientific and experiential knowledge. Competency groups consist of both technical knowledge experts and local knowledge experts and foster an ongoing, open exchange of knowledge and ideas. The process foregrounds how scientists come to know (and model) environmental problems, framing environmental controversies as opportunities for re-envisioning what expertise is, and its role in developing solutions for pressing environmental problems (Whatmore 2009). By generating new knowledge about the environment, the competency group method represents an important shift away from merely gathering local knowledge as data to add to existing environmental models.

Ultimately, for any environmental modeling results to be meaningful, they must be understandable and have the confidence of the public. A transparent modeling process is essential to achieve this confidence and is a prerequisite to the successful outcome of any future modeling activity (Johnson 2008). To maximize transparency, the modeling process should include ongoing, active participation of potentially affected stakeholders in the analysis of environmental problems and in the design of solutions to these problems. Such a co-design process can be a powerful approach to directly engage local residents in the scientific process (Hare et al. 2003). Participatory modeling is a project development technique that allows for two-way communication between local stakeholders and scientists about the problems facing local communities and the co-design of solutions to these problems. The process directly incorporates local and traditional ecological knowledge into models that can help plan and manage coastal protection and restoration (Johnson 2008). Recognizing that the engagement methods used to communicate scenario-based modeling information to local residents may influence their knowledge building and preference judgments (Mavrommati et al. 2017), an active participatory modeling process should incorporate a competency group approach to stakeholder engagement. The competency group approach would allow for the continuous involvement of appropriately representative technical and local knowledge experts and would culminate in the co-development of the ecosystem model that would be used during the participatory modeling process. To assess the effectiveness of such an active participatory modeling approach, this project convened a competency group of technical and local 
knowledge experts with expertise on the Breton Sound Estuary and co-developed two numerical models, a planning-level model and a project-level model. These models were used to assess the effectiveness of a suite of natural and nature-based solutions conceptualized and designed by the competency group.

\section{Study area}

This study focused on communities surrounding the Breton Sound Estuary, an area bounded on the west and north by the Mississippi River, on the south by the Gulf of Mexico, and on the east by the Mississippi River Gulf Outlet (Fig. 1). Study participants were drawn from rural communities in both St. Bernard and Plaquemines parishes (counties). Large portions of these parishes are exposed to tides and waves from the Gulf of Mexico and significant fresh water from multiple connection points with the Lower Mississippi River. The area is composed of shallow water bodies, broken marsh, and a mixture of natural channels and dredged canals. The northern part of the area is mostly fresh and intermediate marsh, gradually transitioning to brackish and saline marsh.

In the wake of Hurricane Katrina in 2005, the majority of residents live within a 100-year federal hurricane flood protection system. However, several small fishing communities located along the bayous that connect Breton Sound to the interior marshes, including Yscloskey, Hopedale, Woodland, Delacroix, and Shell Beach, remain outside federal flood protection. These communities are home to multiple generations of subsistence and commercial fishing families and have been impacted by several large hurricanes as well as the Deepwater Horizon oil spill in 2010. The ZIP Code that encompasses these fishing communities (70085) experienced massive depopulation following Hurricane Katrina, dropping from 7890 people in 2000 to 4427 people in 2010. The most recent US Census data, released in 2017, shows a slight rebound, with the total population climbing to 4878 . Over $81 \%$ of this population is white, and an estimated $26 \%$ lives at or below the federal poverty line.

Research by the Louisiana Coastal Protection and Restoration Authority has identified these areas as being highly dependent on commercial fishing and in need of additional socioeconomic and ecological monitoring (Hijuelos and Hemmerling 2016). Residents of the region often emphasize the ecological, economic, and historical importance of the Breton Sound Estuary in maintaining local culture and livelihoods (Carruthers et al. 2017). For this reason, many of the commercial fisherfolk of the region have historically been engaged in efforts to advise local and state restoration projects.

\section{Public engagement concepts}

The goal of this research was for scientists to collaborate with residents who work in the Breton Sound Estuary to develop, plan, and assess a suite of natural and naturebased solutions and to evaluate the related and potential ecosystem function via a series of participatory modeling scenarios. Two main research questions were asked: 


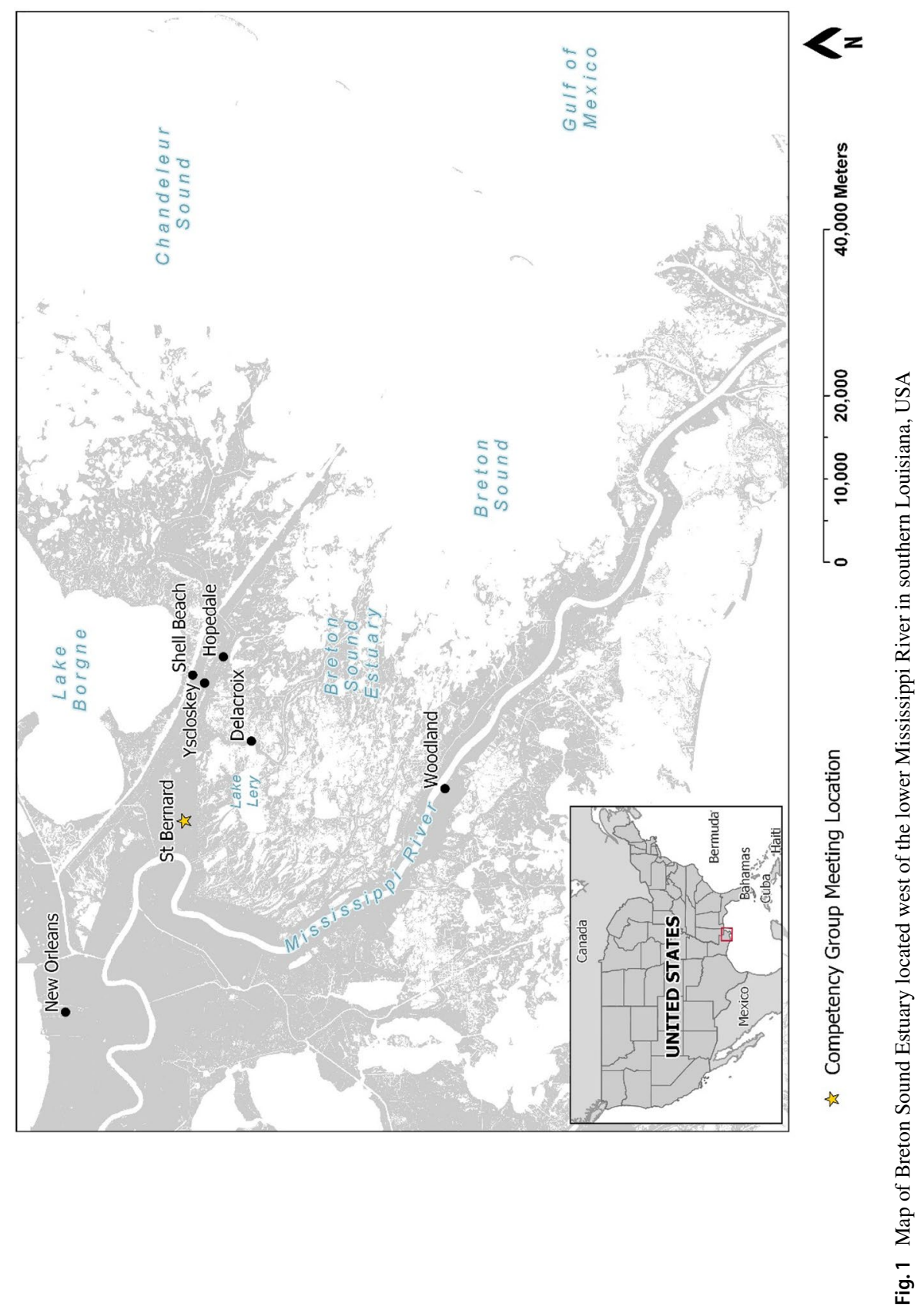


(1) based on the traditional ecological knowledge (TEK) of local residents, what are the possible natural and nature-based solutions to address coastal hazards in and around the estuary?, and (2) how do these nature-based solutions support various ecosystem services? To address these questions, it was necessary to develop a participatory modeling methodology capable of capturing the breadth of knowledge held by coastal Louisiana residents residing around and working within Breton Sound Estuary and incorporating this into a quantitative ecological modeling framework.

Participatory modeling can be broadly conceptualized as a purposeful learning process that engages the implicit knowledge of local residents to create formalized and shared representations of reality (Voinov et al. 2018). The process uses a combination of fact-finding, process facilitation, and modeling to engage non-scientists in the scientific process (Voinov et al. 2018). Stakeholders are expected to engage in all steps of the participatory modeling process. When fully realized, the process will allow residents to utilize their TEK to help structure the problem, describe the system, create an operational computer model of the system, use the model to identify and test policy interventions, and choose one or more solutions based on the model analysis (Stave 2010). While the level of participation of various local stakeholder groups may vary between projects, all stakeholders should understand why particular methods and tools are appropriate at each stage of the process (Voinov et al. 2018).

All of the local residents participating in this project reside around the Breton Sound Estuary, and most were fishermen, shrimpers, and oystermen who utilize the estuary on a daily basis. They were recruited using a peer review selection process, whereby researchers went to local boat launches, seafood processing plants, local coastal zone management boards, and other regional environmental management groups to solicit recommendations on knowledgeable residents with an extensive history and knowledge of the estuary and its surrounding regions (Bethel et al. 2011, 2014; Landström et al. 2011). Researchers kept a running list of names, cross-listing individuals who were frequently recommended based on multiple interactions across groups. The research team strove for occupational, age, and gender diversity among residents, in order to ensure that the selection of members did not overwhelmingly represent commercial and recreational fishing industries. Researchers also asked for non-fishing industry individuals who might be candidates for the working group. There were nine regular participants in the working group: a local fisheries scientist, a recreational fishing guide, a construction business owner, a marina owner, a forester, a resident with extensive land holding in the estuary, and three commercial fishermen (shrimp, crab, and oyster). Each individual was asked to represent his or her own personal interests and knowledge and not act as a representative of any particular political group or set of interests. Honorariums were provided to participating local residents to compensate them for their time and expertise.

The scientists involved were drawn primarily from the Water Institute of the Gulf and included researchers who played key roles in the development of the sediment diversion models used by the State of Louisiana in its Comprehensive Master Plan for a Sustainable Coast (Louisiana Coastal Protection and Restoration Authority 2012, 2017). The research team also extended invitations to scientists from local universities in New Orleans, Baton Rouge, and Lafayette. Due to the long commuting 
distance and high demand of time, however, only scientists from the Water Institute of the Gulf were able to attend all group meetings. There were six regular Water Institute of the Gulf participants: a coastal ecologist, three civil and environmental engineers, a cultural geographer, and an environmental anthropologist.

The full group met on a regular basis over an eight-month period to define the scope and priorities for the creation of a new nature-based solution model and use that model to assess the effectiveness of a suite of coastal protection and restoration projects developed by the group (Hemmerling et al. 2019). Group meetings were not open to the public except when extra hands were needed for photograph or video documentation. This was crucial to building relationships and trust among participants over time. This was also an intentional decision on the part of the researchers to make the meetings working sessions, not public input sessions. The participatory modeling process had three overarching goals:

1. To establish a set of objectives that nature-based solutions should address;

2. To produce formal numerical models that incorporate the combined traditional and scientific knowledge of the competency group members;

3. To explore the extent to which alternative nature-based solutions might be able to address the objectives and develop a list of solutions that the competency group identified as warranting further appraisal.

\subsection{Competency group}

While a number of different participatory modeling approaches have been proposed, this project employed a competency group approach, a process of engagement in which natural and social scientists collaborate over time with residents impacted by flooding in localities in which environmental management is already a source of controversy (Lewis and Ernstson 2017; Whatmore 2009). In southeast Louisiana, public opposition to the planned diversion of Mississippi River water and sediment into the Breton Sound Estuary has coalesced around the impacts of the over-freshening of coastal estuaries and the potential displacement of fisheries (Day et al. 2018). In order to account for this public opposition, as well as the current levels of distrust between residents and scientists, the competency group approach was used to allow residents to play an active role in the development of the numerical models used during the participatory modeling process. The competency group consisted of ten residents and six scientists who met in the town of St. Bernard, LA, on a monthly basis from March to October 2018. These meetings were organized and scheduled to get feedback and insight from locals about the condition of the estuarine system of Breton Sound Estuary, which coastal hazards they are concerned about, and the type of natural and nature-based solutions that could help reduce that hazard. The TEK gathered through this process was used to update the 2017 Louisiana Coastal Master Plan Integrated Compartment Model (ICM) and integrated biophysical Delft3D model that were used during the participatory modeling process. 


\subsection{Participatory modeling}

Participatory modeling involves the active and direct participation of local residents in model formulation and in the process of building the model itself. Residents provide input to the model, contribute to the identification of model components, the linkages of these components, and the dynamics between and among components (Mendoza and Prabhu 2005). The process integrates local knowledge with accumulated technical scientific knowledge, leading to an improved understanding of a system's interactions and behavior, allowing local residents to contribute information regarding the coastal restoration planning process within their own communities (Carruthers et al. 2017). However, for the process to be embraced at the local level, participatory modeling must represent scientific knowledge in a simple and transparent way, stripped of the complexity that often characterizes numerical models (Voinov and Gaddis 2008). The competency group method accomplished this by allowing the numerical models to be co-developed with direct input from residents. These co-developed models were used during the participatory modeling phase of the research to test the ability of nature-based solutions and restoration projects identified by the competency group as having potential to enhance the stability and resilience of the region.

\section{Methods}

\subsection{Workshop facilitation}

The participatory modeling component of the project took place from June through October 2018 and included two meetings of the full competency group. Data were gathered through facilitated small group discussions and local knowledge mapping (LKM) exercises. LKM is a technique that encourages participants to identify areas of value or concern that are not readily available through traditional quantitative and cartographic methods (Clavel et al. 2011; Curtis et al. 2018). This method is a powerful way to integrate qualitative data into quantitative ecological models that can support decision-making in regard to coastal protection and restoration (Carruthers et al. 2017). Facilitation of the LKM exercise began by dividing the competency group members into five competency mapping groups containing between four and five participants each, including both scientific and local knowledge experts. Dividing the competency group into smaller competency mapping groups provided the opportunity for in-depth discussion about the possible outcomes, benefits, and constraints of each proposed project, resulting in a wider range of nature-based solutions to assess.

Each competency mapping group marked and annotated a base map, identifying and labeling locations in the estuary where group members believed specific naturebased solutions would provide the greatest resilience benefits. The base maps developed for the LKM effort provided enough key contextual information to the group members to allow them to easily identify geographic features while not influencing the project development process (Fig. 2). Contextual information was limited to the 


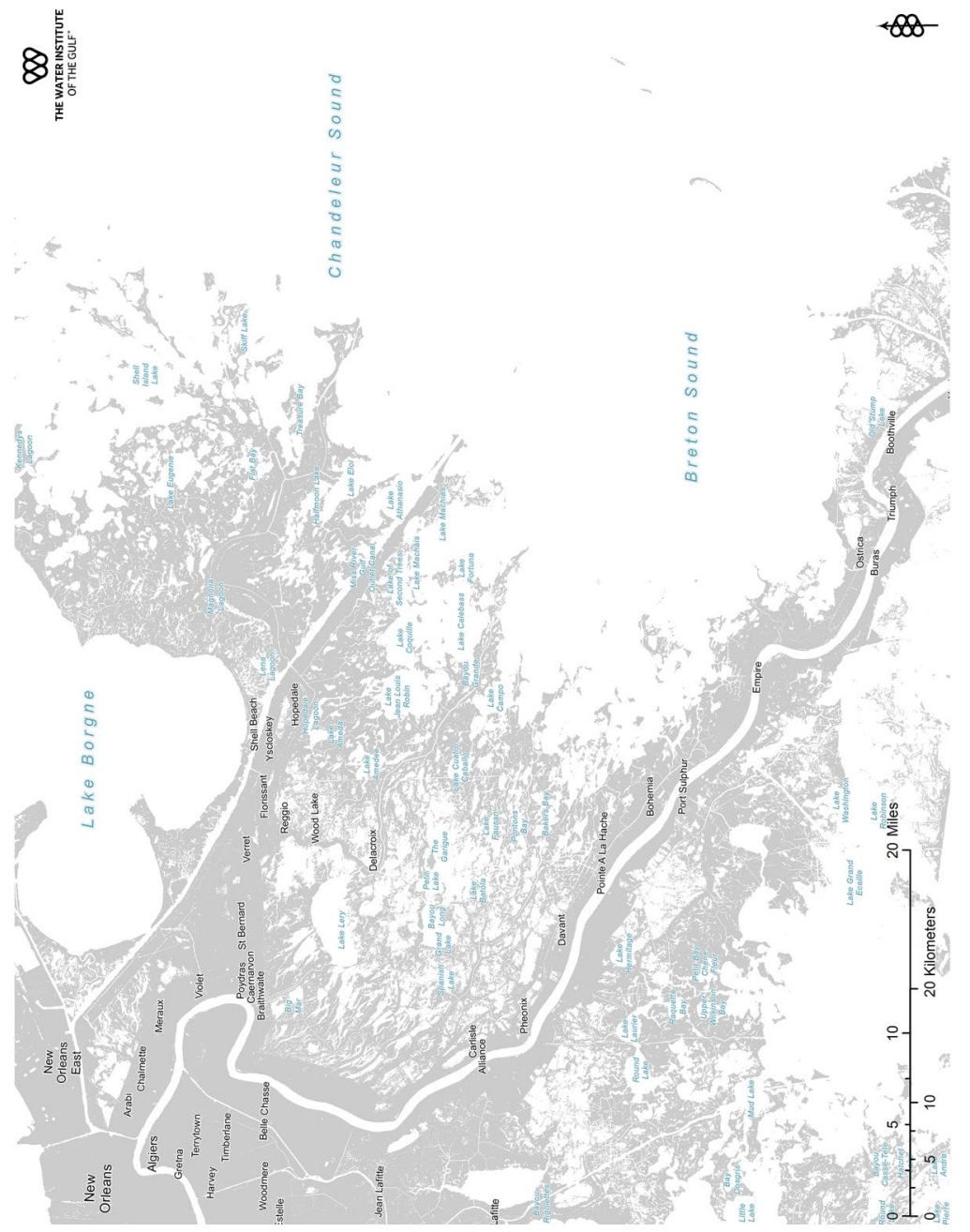

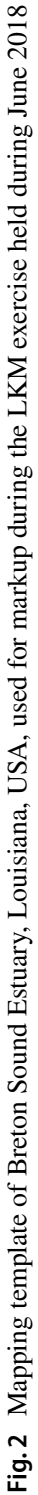




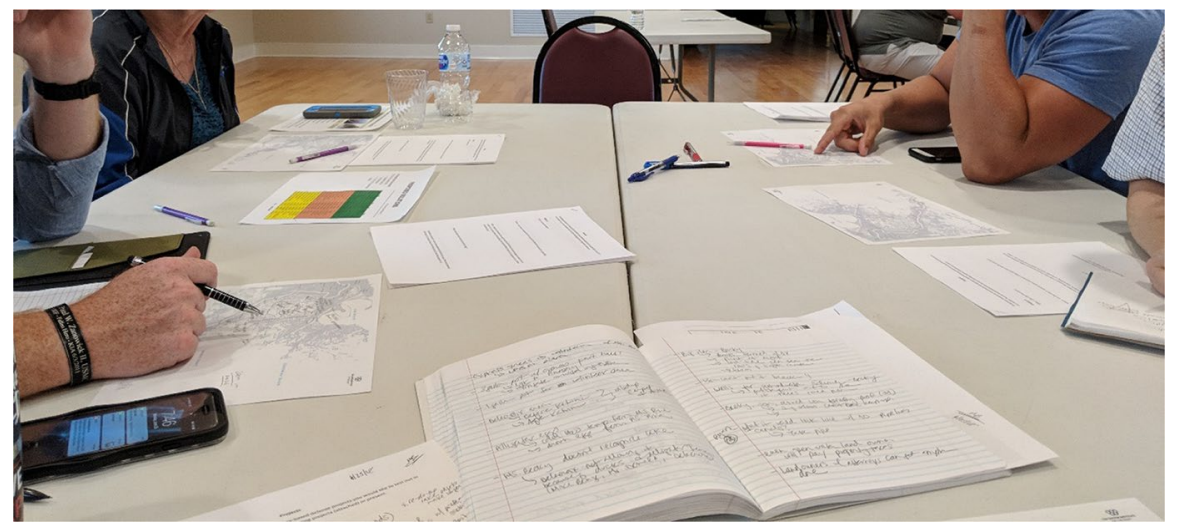

Fig. 3 Competency mapping groups discuss project selection and model development

current land-water interface and labels for significant waterbodies as well as towns, villages, and cities within the study area. ${ }^{1}$

Participants also filled out an associated LKM worksheet to provide additional details on the project being developed, including information on the goals of the project and the scenarios that they wanted the project to be tested under (Fig. 3). The LKM worksheet is in paper format and two pages in length. The first page of the worksheet is comprised of five questions focusing on specific nature-based solutions that each competency mapping group wanted to use the models to test. The second page focuses on the different scenarios that group members wanted to test these solutions under. The competency group meetings were also audio recorded with participants' consent, transcribed, and coded to provide additional detail and clarification on the projects and scenarios that may not have been captured in the worksheets.

\subsection{Project and scenario development}

Participants were provided with a hard copy of the LKM template and subsequently guided through the process of nature-based solution project selection and scenario identification through use of the LKM worksheet. Project-specific prompts asked participants to: (a) describe the nature-based solution they were interested in implementing, (b) spatially locate the identified nature-based solution on a map, (c) categorize the desired outcomes motivating project selection, (d) identify a model output that could quantify the outcomes, and (e) identify specific benefits or constraints associated with implementation of the identified solution (e.g., synergy with existing solutions, changes to flood risk, likelihood of funding approval, potential concerns

\footnotetext{
1 The land-water interface geodata was originally created for the 2017 Coastal Master Plan. Place geodata was pulled from the U.S. Bureau of Census' publicly available TIGERLine database. Water bodies and waterway flow lines were adapted from the U.S. Geological Survey's National Hydrography Dataset.
} 
with project longevity). Scenario-specific prompts asked participants to identify potential scenarios to test the identified solutions against. Scenario examples were provided to the competency group and included adjustments to rate of sea level rise, performance against historic storm tracks and intensities, modifications to known subsidence rates, alterations to the frequency of drought, high-intensity rainfall, riverine flooding from the Mississippi River, and variations in storm surge or windbased scenarios. Other potential scenarios included anthropogenic alterations to the landscape, such changes to the operating regime of sediment diversion projects in Breton Sound, and the inclusion or exclusion of 2017 Coastal Master Plan projects. To clarify the applicability of a given scenario, participants were also asked to identify the outcomes the scenario was designed to analyze (e.g., changes to salinity, changes to vegetation, land building potential).

Following the competency group's selection of desired restoration projects and scenarios, the project team transformed the LKM annotations into a digital form by scanning the paper map output and georeferencing them in a geographic information system (GIS) (Fig. 4). The research team then digitized the project's footprint and created unique feature classes for each project (Fig. 5). All three types of general GIS feature classifications (point, line, and polygon) were required based on the range of projects selected by the competency group. Point features were used to indicate a discrete project location, including the site of an existing rock dam identified for removal and the location of new river diversion structure. Line features were used to show the spatial extent of project classes that are typically linear in nature. Examples of linear features identified through the LKM process include the placement of shoreline protection structures and the infilling of oil and gas pipeline canals. Finally, polygon features were used to identify the areal extent of a restoration project's footprint when a discrete point or line was not descriptive enough to illustrate the wider impact of the identified project. This included the placement of marsh creation projects and the areal extent of terracing projects meant to capture sediment and build land. Each of the digitized features was classed based on the type of nature-based defense and assigned a unique identifier based on the mapping group that developed the project. Data derived from the LKM worksheets were also entered into the GIS data tables and used to provide additional classification data for each project. All digitized projects were packaged in a geodatabase and provided to the modeling team for evaluation. The modeling team adapted the generalized project feature to the landscape to assure comparability with the models, and the final project footprints (Fig. 6) were reviewed and edited by the full competency group.

\subsection{Project and scenario modeling}

Two numerical models were adapted by the competency group and used to test the ability of the planned nature-based solutions to achieve the desired outcomes (Meselhe et al. in press). The Integrated Compartment Model (ICM), a planninglevel tool developed for Louisiana's 2017 Coastal Master Plan, has a large grid size and a relatively fast computing time (Louisiana Coastal Protection and Restoration Authority 2017). This comprehensive landscape model, referred to by the 


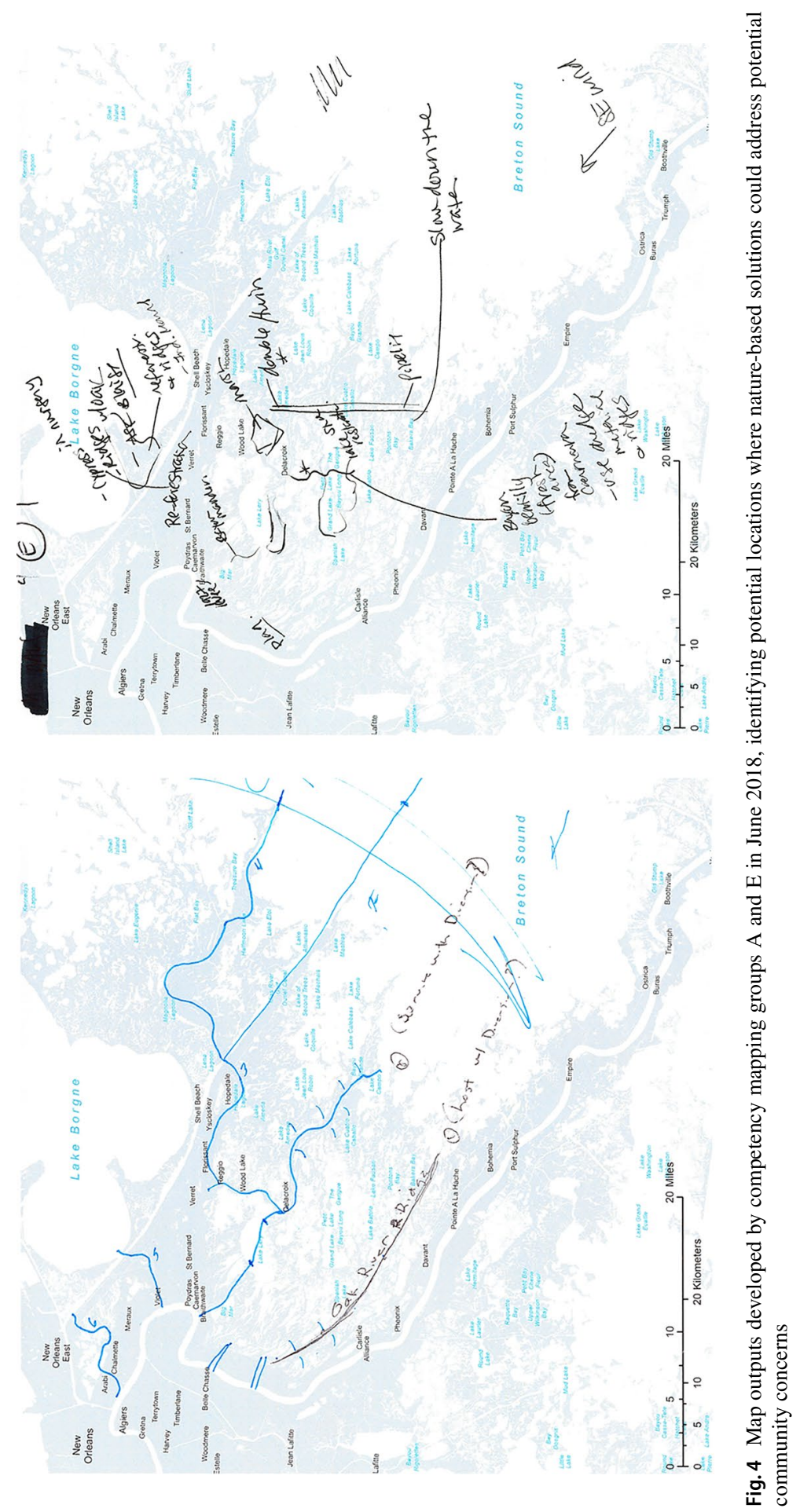




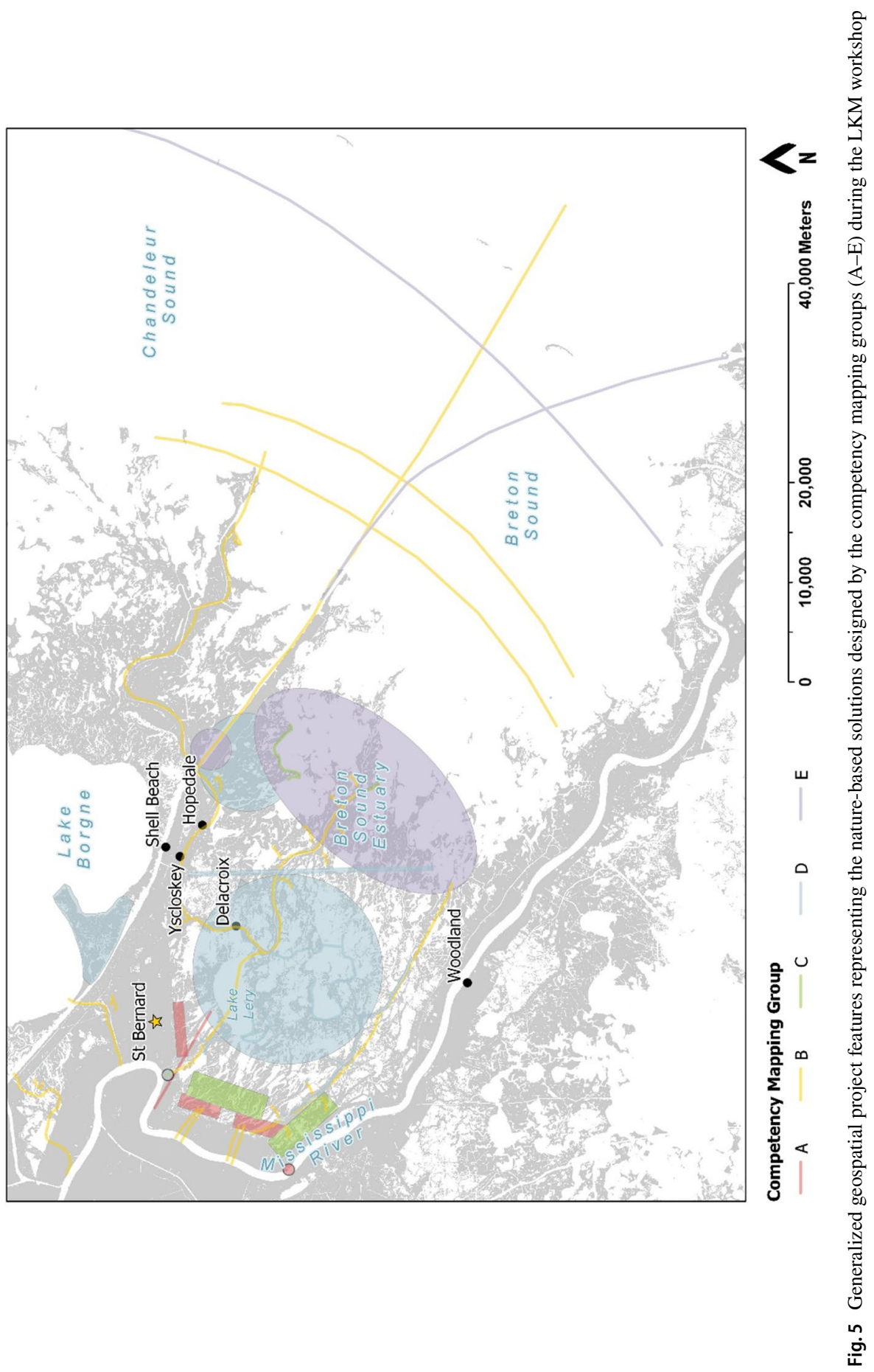




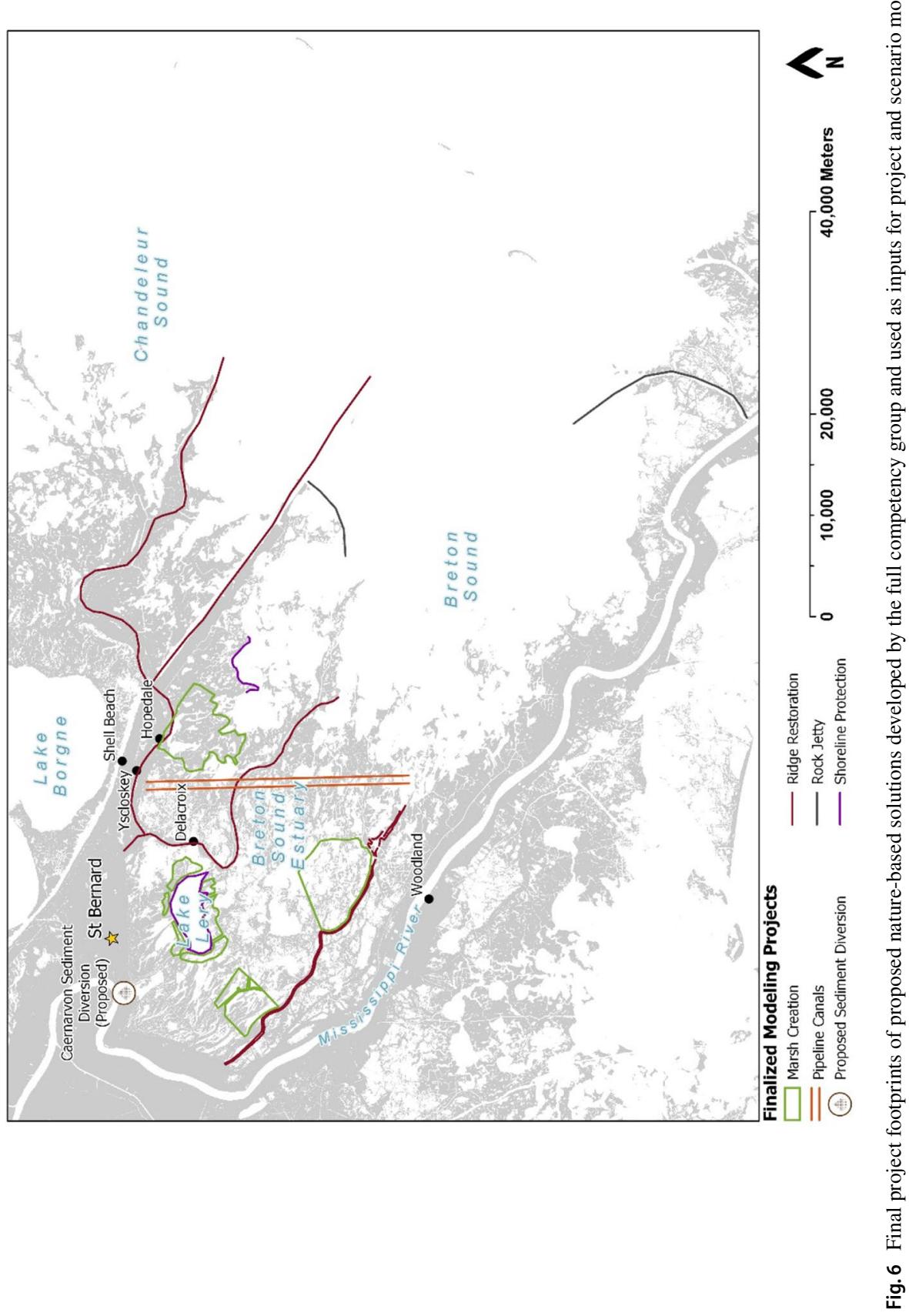


competency group as the "fast model," was used to perform decadal simulations and examine the impact of environmental drivers on coastal ecosystems. The ICM was used to assess how salinity and water level variability affect the spatial distribution of vegetation taxa as well how hydrodynamic forcings and marsh edge erosional processes impact wetland loss rates. The ICM was also used to assess how changes in organic matter accretion and sediment deposition impact wetlands under a number of sea level rise scenarios (Alymov et al. 2017).

The second model used to test the effectiveness of the proposed nature-based solutions was the Integrated Biophysical Model (IBM), a project-level Delft3D model that has small grid cells and a slow computing time, referred to by the group as the "slow model" (Baustian et al. 2018; Meselhe et al. 2015). The IBM couples hydrodynamics, nutrient dynamics, vegetation dynamics, and morphodynamics to model changes to wetland vegetation and estuarine open water (Baustian et al. 2018). Additionally, scenarios that included future environmental conditions (sea level rise and subsidence) and the impacts of hurricane-force winds, water levels, and drought conditions were run with the IBM.

Due to computing time and computational resources required to run the models, many of the projects proposed by the competency group were initially screened and evaluated using the ICM. When the initial model results from the ICM-suggested potential benefits from particular projects, these projects were then evaluated using the IBM. Because conducing model runs with the IBM is computationally expensive and time consuming, this model was strategically used in a select number of simulations to illustrate the response of the landscape to the implementation of nature-based solutions under select environmental conditions. The advantages and disadvantages of both models were discussed with the competency group prior to the participatory mapping exercise to determine which model best captures the ecological, hydrological, and morphological aspects of the estuary that participants were interested (Table 1).

\section{Results}

A total of 21 natural and nature-based solutions (named with the prefix $P X X X$ ) were catalogued based on input from the full competency group. Of these 21 projects, one was outside of the model domain and four were deemed duplicative of other proposed projects and combined, leaving 16 projects to be modeled (Table 2). Ridge restoration and marsh creation projects were most frequently recommended by the competency mapping groups during the LKM workshops. Ridge restoration was also identified as the single most important nature-based solution in a survey of competency group members conducted at the conclusion of the project.

The competency group proposed four main marsh creation projects (P001, P009, P011, and P012) as nature-based solutions in Breton Sound Estuary. Three of the created marshes were designed to fill in the shallow open water and restore the marsh habitat, and the fourth was to maintain the shoreline edge around Lake Lery. Model run scenarios for these projects also included the operation of the proposed Mississippi River sediment diversion project proposed by CPRA (Mid-Breton 


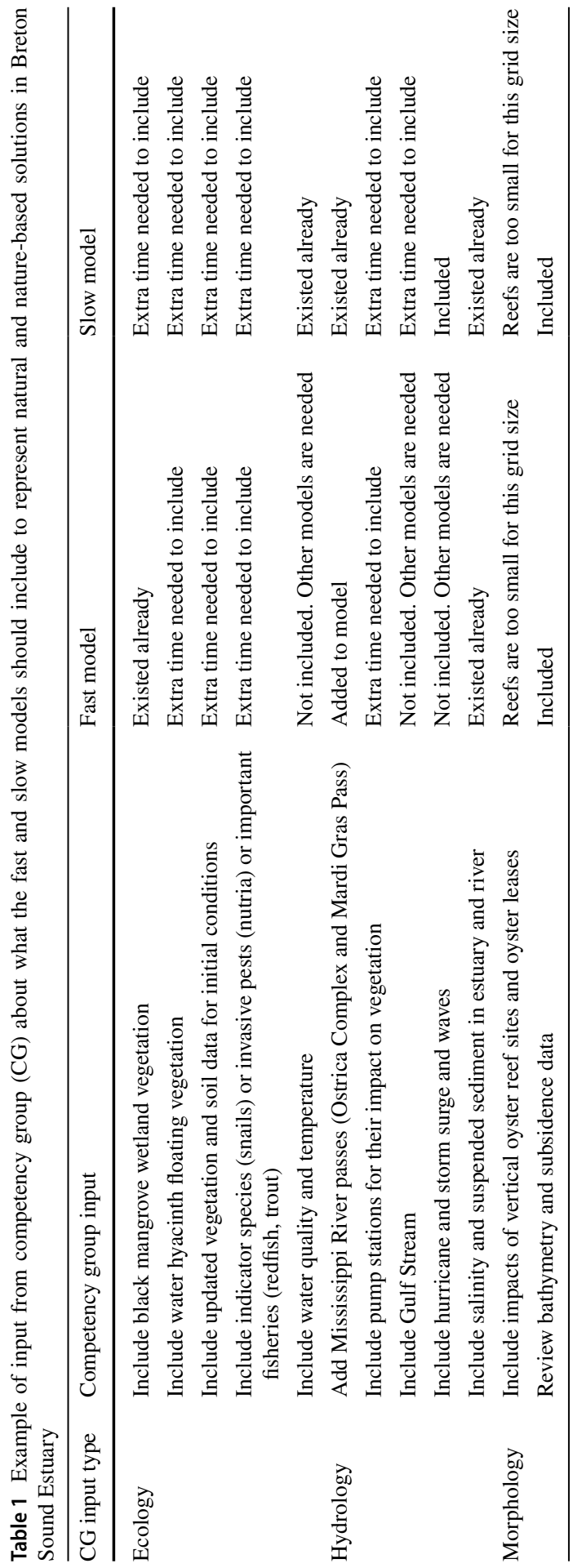




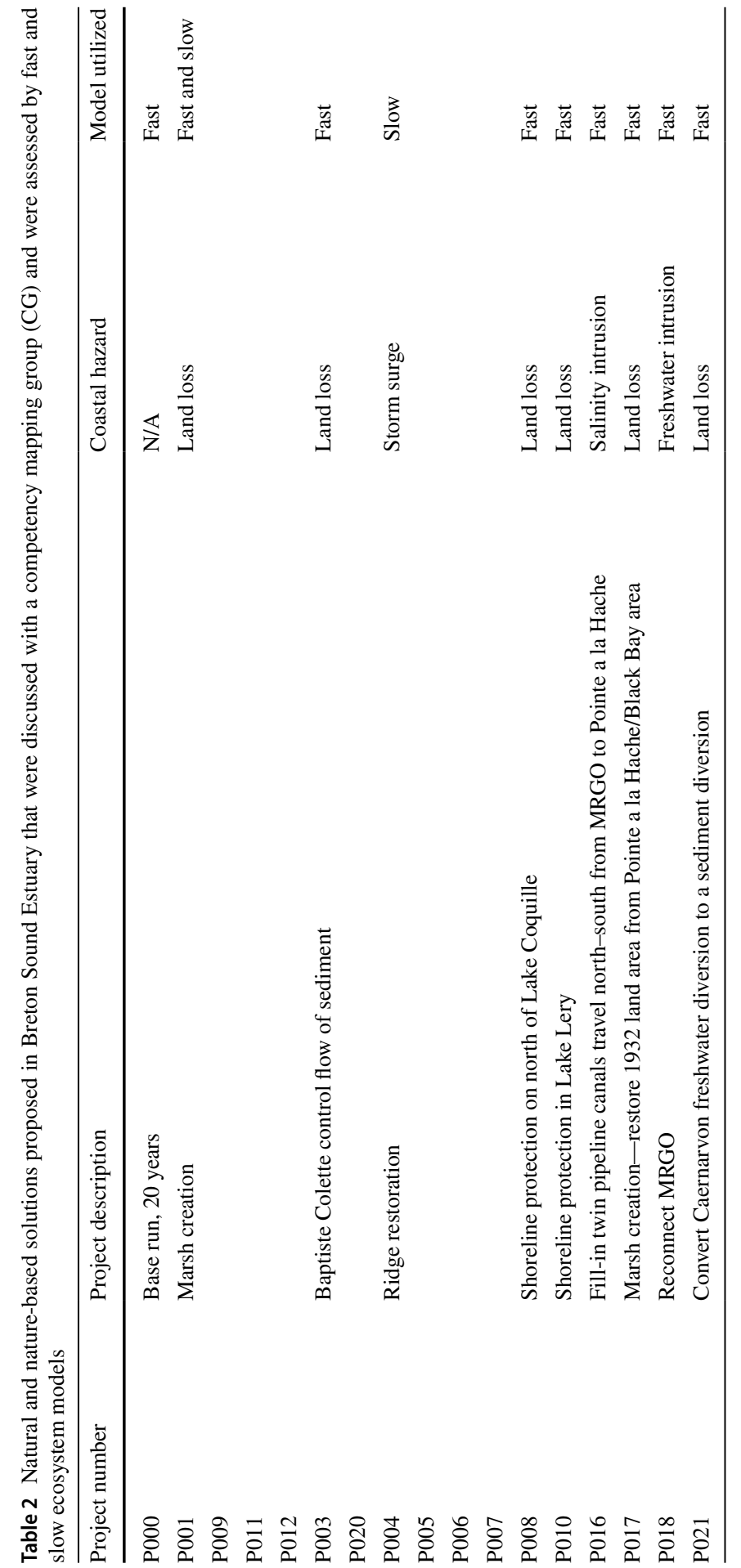


Sediment Diversion). The potential ecosystem functions evaluated for these naturebased solutions include nutrient uptake, fisheries habitat, and soil carbon storage. The group also proposed a series of ridge restoration projects (P004, P005, P006, and P007) to protect residents living proximate to Breton Sound Estuary. The group members were most interested in how these ridges could dampen the water levels from major weather events like a strong and persistent southeast wind or hurricaneforce winds. To test this, model run scenarios for these projects used 2005's Hurricane Katrina as a template.

Projects with the same desired restoration outcomes (e.g., Marsh Creation: P001, P009, P011, and P012) were consolidated into single model runs to save computing resources, resulting in nine grouped projects to evaluate. The most appropriate ecosystem model was chosen based on the model's capability to evaluate each naturebased solution and environmental scenario identified by the competency mapping groups in the LKM surveys. For example, the ICM was utilized to determine whether land loss could be slowed down by the proposed marsh creation projects (P001, P009, P011, and P012), and then, the IBM was run to provide more detailed outputs. Conversely, because the ICM does not possess the capabilities to model storm surge, the ridge restoration projects (P004, P005, P006, and P007) were only run with the IBM to see if these projects could protect coastal communities under future storm scenarios. The majority of these project groupings were evaluated at year 20 to assess the potential ecosystem function with and without nature-based solutions. For the storm surge and constant wind simulations used to assess the effect of ridge restoration on water elevation, the model utilized year 0 (current conditions) data only. The first model run (P000) included no new nature-based solution features so that it can be compared to the other model runs that included proposed nature-based solutions.

While several project types were evaluated by the competency group, the results of the marsh creation and ridge restoration projects noted above are discussed here. Initial project evaluation of marsh creation projects coupled with terrace features using the ICM shows increases in both sediment accretion and water level upstream of the terraces. A net land loss was predicted at year 20 due to the localized inundation-related stressors to the wetland vegetation. Project evaluation with the IBM shows no significant impact on the hydrological condition (mean water level, salinity, sediment accretion) in the project area at year 10 .

The evaluation of the ridge restoration projects using the IBM shows that restoring historical ridge features can block and reduce storm surge heights locally. However, the ridges can also trap surge flow, resulting in increases in surge height in other locations, suggesting a trade-off in costs and benefits of the project. This is because surge height is highly dependent on wind direction and storm path. When the impacts of a strong, constant wind was modeled, the results show that water levels on the backside of ridges were reduced until water levels reached the ridge elevation. However, similar to the impacts of storm surge, the presence of ridges increased the local water elevation due to the ridges trapping water. Water elevation changes were highly related to the wind direction and orientation of ridges.

The results of these model runs were presented to the competency group during the final meeting of the group. Project fact sheets were developed for each of 


\title{
Historical Ridge Restoration
}

\author{
Ridge Restoration \\ Project Number: P004, P005, P006, and P007
}

\section{Project Description}

Restoration of the historical ridges: 1) Ridge restoration south of Big Mar (P004); 2) Ridge restoration west of Lake Leary (P005); 3) Ridge restoration of old river channels (P006); 4) Ridge restoration of Oak River, Bayou La Loutre and Terre aux Boeufs (P007). These projects were intended to provide coastal upland habitat, restore natural hydrology, and provide wave and storm surge attenuation.

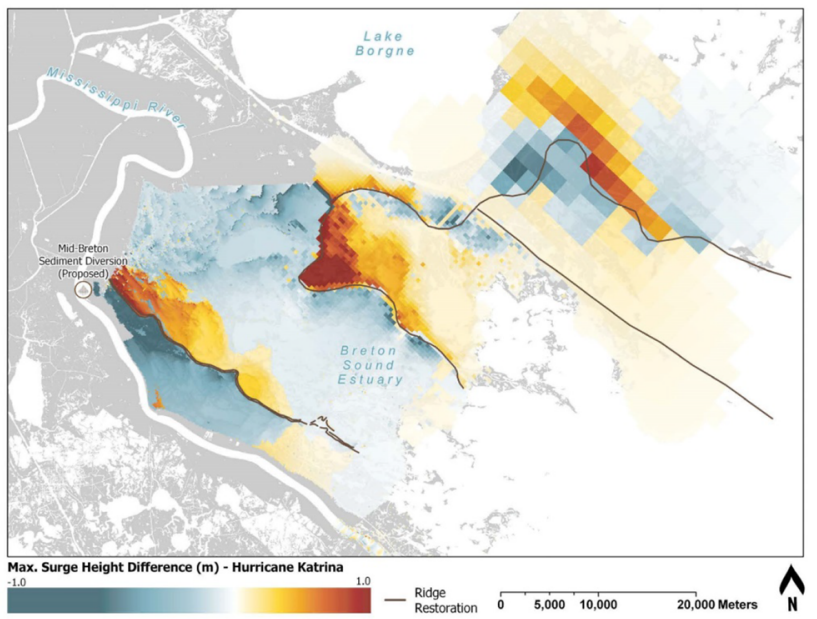

\section{Modeling Comments}

Hurricane Katrina (2005) was considered to evaluate the effects of restoration of historical ridges ( $+1.5 \mathrm{~m}$ (NAVD 88)) in the bay. The evaluation using the slow model shows that the restoration of ridges can reduce surge heights locally by blocking storm surge. However, the ridges can also trap surge flow, resulting in increases of surge height locally. It is because the surge height change is highly dependent on the wind direction and hurricane path. The evaluation using constant wind ( $30 \mathrm{~m} / \mathrm{s}$ from SE dir.) shows that water levels on the backside of ridges were reduced $(<10 \mathrm{~cm})$ until the point in which water levels reached the ridge elevation. However, the existence of ridges locally increased the water elevation $(>10 \mathrm{~cm})$ due to the ridges trapping water. Water elevation changes were highly related to the wind direction and orientation of ridges.

\section{Scenarios Considered}

Low, medium, and high environmental scenarios

\section{Approximate Project Cost*}

$\sim$ \$100 million

* Cost is estimated from the average unit cost of ridge restoration projects located in the Breton basin that were included in the 2017 Coastal Master Plan; the average cost was $\$ 188$ per linear foot. These project unit costs do not account for any site-specific elements, sediment volumes required, nor account for other project constraints.

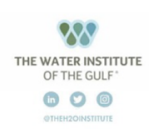

Fig. 7 Example draft project summary sheet presented to the competency group in October 2018 for review

the nine project groupings, providing a detailed description of the project, the scenarios considered in the model runs, comments from the modeling team describing the results of each model run, and an approximate project cost (Fig. 7). The project unit costs were based on average values used in the 2017 Coastal Master Plan and provided as a means to illustrate the potential scale of a project's overall cost rather than provide a detailed estimate as it was not feasible to capture any site-specific 
Table 3 Survey questions used to assess the effectiveness of the competency group process

Meeting logistics

1. Quality of the meeting preparation and communication

2. Clarity of project goals

3. Meeting organization and conduct

4. All opinions were considered during the group meetings

Meeting outcomes

1. Do you feel like your voice was heard during our group meetings?

2. Do you feel that your perspective was represented in the restoration projects?

3. Did your opinions and understanding of restoration projects change over the course of our meetings?

4. Did your understanding of the modeling process change over the course of the group meetings?

5. Do you feel certain members of the group had too much of an influence over selected projects and models?

6. Do you feel like you learned something from your collaborators?

7. Do you feel that the groups' models and projects are distinct from state projects and processes (i.e., CPRA/CWPPRA)?

8. Overall, do you feel that the project outcomes reflected the project goals?

restoration elements or other project constraints. Following a final review by the full competency group, the fact sheets were bound and presented to each of the group members. Digital versions of this booklet were also provided electronically to ensure that the results of this process could be easily disseminated.

At the conclusion of this process, a paper survey was provided to all group members to allow them to provide feedback on the participatory modeling process. A total of ten group members participated in the survey, which contained a series of short, open-ended questions and 12 questions with a Likert-type scale (from poor to excellent) to assess aspects of the meeting process and logistics (Table 3). Overall, the survey results suggest that the participatory modeling approach can be an effective way to update ecosystem models and test ideas about potential natural and nature-based solutions to coastal hazards (Meselhe et al. in press). With regard to meeting logistics, respondents consistently assessed the quality and organization of the meetings, clarity of the goals, and the consideration of all opinions in the good to very good range. Group members found the process to be "fundamentally different" from other coastal planning and science meetings as public input "was sought prior to modeling efforts." Additionally, group members noted that this process was more inclusive and involved a more diverse group of participants than "the usual coastal planning meetings" and that "most coastal planning meetings don't include people from the community."

Likewise, the meeting outcomes were generally deemed successful by group members, who highly ranked their responses about learning something from this collaboration, that their voices were heard, and that certain members did not have too much of an influence on the discussion and decision to include natural and nature-based projects or adjustments to the models. One group member noted that participatory modeling should "absolutely" be included in future coastal planning 
processes and that the process allowed for a true "exchange of ideas between residents and scientists." This exchange of ideas resulted in an enhanced co-learning process, whereby scientists learned that the public is "quite knowledgeable about the systems dynamics" and the public learned that the models have tremendous benefits but that they also have their limitations. It is these last points that perhaps explain the lowest ranked response from group members, many of whom felt that the final models were only moderately distinct from other models developed by state agencies. One group member noted that the overall results could have been improved if the scientists gave more consideration to making changes to the "default model conditions." Yet this shortcoming was generally viewed as something that could be overcome with "more time or a longer project duration." Most group members felt that continued engagement was a key to the success of the participatory modeling process. Ultimately, by working together over an 8-month period, the group felt that they were able to effectively bridge perceived knowledge gaps and foster an increased sense of trust between scientist and residents, which allowed modeling information and traditional ecological knowledge to be more effectively co-delivered and co-shared.

\section{Conclusions}

For coastal protection and restoration to proceed in a socially just manner, the coastal planning process will need to strike an effective balance between science-driven processes and engagement with residents and stakeholder groups. This is especially important in areas vulnerable to risk as well as those likely to be affected by policy actions (Hemmerling et al. 2019). Such collaborative natural resource management process requires a combination of descriptive and prescriptive knowledge as well as local capacity and desire for change. Because local resource beneficiaries in coastal Louisiana, and in most if not all coastal communities in general, have such knowledge and capacity, localized engagement is crucial to the successful implementation of coastal protect and restoration projects. The people who live and work in coastal communities have developed a wealth of knowledge from their experiences and should be considered as valid "sensors" of their environment (Goodchild 2007). Despite the presence of this evidence base, it remains effectively untapped. This can be attributed to the fact that there are often overlapping layers of power between scientists and local residents - often with scientists leading the projects and dominating the balance of power due to their academic status and wider access to funding and formal education (Jordan et al. 2018). Regardless of scientific intention, this can create a cycle of repudiation often at odds with the endgame of unbiased decision-making (Steel and Whyte 2012). Indeed, the extant research has overwhelmingly relied on "official" data to understand and then proscribe actions to promote resilience.

This project took a different tack by elevating local knowledge as a scientific data source and collecting and analyzing it in ways that are systematic, rigorous, and replicable to create a model of community-informed resilience in concert with actionable policy (Curtis et al. 2018). Application of participatory modeling methods for modeling complex coastal environments can help incorporate stakeholder 
input into a traditionally analytical decision-making process. Used properly, it can be an important tool in fostering stakeholder buy-into the oft-contentious solutions posited by organizations charged with coastal restoration activities. An extra-disciplinary approach, when applied to modeling efforts or any solely scientific process, can account for localized knowledge often overlooked during consolidation of a study domain's knowledge base. Participatory modeling is particularly compatible with the rising focus on integrated natural resources management grounded in systems theory aiming to improve resource resiliency while still accounting for the socioeconomic concerns of the surrounding community (Voinov and Gaddis 2008). Such an integrated systems management approach requires development of solutions for unique local situations, a task that is supported by engaging stakeholders in the research process through collection of traditional ecological knowledge. Participatory modeling, as demonstrated in this effort, provides a useful platform for amalgamating scientific understanding with local knowledge. When executed effectively, it can provide an objective forum for a diverse group of stakeholders to contribute information regarding issues important to them.

Acknowledgements This project was supported by the Science and Engineering Plan of The Water Institute of the Gulf with funds from the Louisiana Coastal Protection and Restoration Authority (CPRA) and the Baton Rouge Area Foundation (BRAF). We would like to thank the Los Isleños Heritage and MultiCultural Park for hosting the competency group meetings and the community members for taking time out of their busy schedules to be part of this competency group and discuss coastal hazards and natural and nature-based solutions.

Open Access This article is distributed under the terms of the Creative Commons Attribution 4.0 International License (http://creativecommons.org/licenses/by/4.0/), which permits unrestricted use, distribution, and reproduction in any medium, provided you give appropriate credit to the original author(s) and the source, provide a link to the Creative Commons license, and indicate if changes were made.

\section{References}

Alymov V, Cobell Z, de Mutsert K, Dong Z, Duke-Sylvester S, Fischbach J, Hanegan K, Lewis K, Lindquist D, McCorquodale JA, Poff M, Roberts H, Schindler J, Visser JM, Wang Z, Wang Y, White E (2017) 2017 coastal master plan: appendix C: modeling chapter 4-model outcomes and interpretations. Coastal Protection and Restoration Authority, Baton Rouge, pp 1-448

Arkema KK, Griffin R, Maldonado S, Silver J, Suckale J, Guerry AD (2017) Linking social, ecological, and physical science to advance natural and nature-based protection for coastal communities. Ann $\mathrm{N}$ Y Acad Sci 1399(1):5-26

Barbier EB, Hacker SD, Kennedy C, Koch EW, Stier AC, Silliman BR (2011) The value of estuarine and coastal ecosystem services. Ecol Monogr 81(2):169-193

Bargu S, Justic D, White JR, Lane R, Day J, Paerl H, Raynie R (2019) Mississippi River diversions and phytoplankton dynamics in deltaic Gulf of Mexico estuaries: a review. Estuar Coast Shelf Sci 221:39-52

Barra M (2016) Natural infrastructures: sediment, science, and the future of southeast Louisiana [Blog post]. Retrieved from https://aesengagement.wordpress.com/2016/03/22/natural-infrastructures -sediment-science-and-the-future-of-southeast-louisiana/

Barra M (2017) The new cartographers. Louisiana Cultural Vistas (Winter)

Barras J, Beville S, Britsch D, Hartley S, Hawes S, Johnston J, Kemp P, Kinler Q, Martucci A, Porthouse J, Reed D, Roy K, Sapkota S, Suhayda J (2003) Historical and projected coastal Louisiana land changes: 1978-2050 (No. Open File Report 03-334). U.S. Geological Survey, p 39 
Baustian MM, Meselhe E, Jung H, Sadid K, Duke-Sylvester SM, Visser JM, Allison MA, Moss LC, Ramatchandirane CG (2018) Development of an integrated biophysical model to represent morphological and ecological processes in a changing deltaic and coastal ecosystem. Environ Model Softw 109:402-419

Bethel MB, Brien LF, Danielson EJ, Laska SB, Troutman JP, Boshart WM, Giardino MJ, Phillips MA (2011) Blending geospatial technology and traditional ecological knowledge to enhance restoration decision-support processes in coastal Louisiana. J Coast Res 27(3):555-571

Bethel MB, Brien LF, Esposito MM, Miller CT, Buras HS, Laska SB, Philippe R, Peterson KJ, Parsons Richards C (2014) Sci-TEK: a GIS-based multidisciplinary method for incorporating traditional ecological knowledge into Louisiana's coastal restoration decision-making processes. J Coast Res 30:1081-1099

Bethel MB, Laska SB, Gremillion MM, Brien LF, Peterson KJ, Philippe R, Richards CP (2015) Sci-TEK: mapping traditional ecological knowledge of Barataria basin with spatial and science-derived datasets. Louisiana Coastal Protection and Restoration Authority, Baton Rouge, p 252

Blum MD, Roberts HH (2009) Drowning of the Mississippi Delta due to insufficient sediment supply and global sea-level rise. Nat Geosci 2:488-491

Boesch DF (2006) Scientific requirements for ecosystem-based management in the restoration of the Chesapeake Bay and coastal Louisiana. Ecol Eng 26:6-26

Boesch DF, Josselyn MN, Mehta AJ, Morris JT, Nuttle WK, Simestad CA, Swift DJP (1994) Scientific assessment of coastal wetland loss, restoration and management in Louisiana. J Coast Res Spec Issue 20:1-103

Carruthers TJ, Hemmerling SA, Barra M, Saxby TA, Moss L (2017) This is your shield...this is your estuary: building community resilience to a changing Louisiana coastline through restoration of key ecosystem components (No. WISR-002-2017). The Water Institute of the Gulf, Baton Rouge, p 48

Castelletti A, Soncinisessa R (2006) A procedural approach to strengthening integration and participation in water resource planning. Environ Model Softw 21(10):1455-1470

Chesney EJ, Baltz DM, Thomas RG (2000) Louisiana estuarine and coastal fisheries and habitats: perspectives from a fish's eye view. Ecol Appl 10(2):350-366

Clavel L, Soudais J, Baudet D, Leenhardt D (2011) Integrating expert knowledge and quantitative information for mapping cropping systems. Land Use Policy 28(1):57-65

Colten CE, Simms JRZ, Grismore AA, Hemmerling SA (2018) Social justice and mobility in coastal Louisiana, USA. Reg Environ Change 18(2):371-383

Couvillion BR, Beck H, Schoolmaster D, Fischer M (2017) Land area change in coastal Louisiana (1932 to 2016) (No. Scientific Investigations Map 3381). US Department of the Interior, US Geological Survey, Reston, p 26

Curtis JW, Curtis A, Hemmerling SA (2018) Revealing the invisible environments of risk and resiliency in vulnerable communities through geospatial techniques. In: Barberopoulou A (ed) Tsunamis: detection, risk assessment and crisis management. Nova Science Publishers, Hauppauge

Dalbom C, Hemmerling SA, Lewis JA (2014) Community resettlement prospects in southeast Louisiana: a multidisciplinary exploration of legal, cultural, and demographic aspects of moving individuals and communities (issue paper). Tulane Institute on Water Resources Law \& Policy, New Orleans, p 49

Day JW, Britsch LD, Hawes SR, Shaffer GP, Reed DJ, Cahoon D (2000) Pattern and process of land loss in the Mississippi Delta: a spatial and temporal analysis of wetland habitat change. Estuaries 23(4):425

Day JW, Kemp GP, Reed DJ, Cahoon DR, Boumans RM, Suhayda JM, Gambrell R (2011) Vegetation death and rapid loss of surface elevation in two contrasting Mississippi Delta salt marshes: the role of sedimentation, autocompaction and sea-level rise. Ecol Eng 37(2):229-240

Day JW, Lane RR, D'Elia CF, Wiegman ARH, Rutherford JS, Shaffer GP, Brantley CG, Paul Kemp G (2018) Large infrequently operated river diversions for Mississippi Delta restoration. In: Day JW, Erdman JA (eds) Mississippi Delta restoration. Springer, Cham, pp 113-133

Gedan KB, Kirwan ML, Wolanski E, Barbier EB, Silliman BR (2011) The present and future role of coastal wetland vegetation in protecting shorelines: answering recent challenges to the paradigm. Clim Change 106(1):7-29

Goodchild MF (2007) Citizens as sensors: the world of volunteered geography. GeoJournal 69(4):211-221

Hare M, Letcher RA, Jakeman AJ (2003) Participatory modelling in natural resource management: a comparison of four case studies. Integr Assess 4(2):62-72 
Hemmerling SA, Barra M, Bond RH (2019) Adapting to a smaller coast: restoration, protection, and social justice in coastal Louisiana. In: Laska $\mathrm{S}$ (ed) Louisiana's response to extreme weather: a coastal state's adaptation challenges and successes. Springer, Cham

Hijuelos AC, Hemmerling SA (2016) Coast wide and basin wide monitoring plans for Louisiana's System Wide Assessment and Monitoring Program (SWAMP) (Version 3). The Water Institute of the Gulf, Baton Rouge, p 205 (Prepared for and funded by the Coastal Protection and Restoration Authority (CPRA) under Task Order 6, Contract No. 2503-12-58, Baton Rouge, LA)

Johnson MS (2008) Public participation and perceptions of watershed modeling. Soc Nat Resour 22(1):79-87

Jordan R, Gray S, Zellner M, Glynn PD, Voinov A, Hedelin B, Sterling EJ, Leong K, Olabisi LS, Hubacek K, Bommel P, BenDor TK, Jetter AJ, Laursen B, Singer A, Giabbanelli PJ, Kolagani N, Carrera LB, Jenni K, Prell C, National Socio-Environmental Synthesis Center Participatory Modeling Pursuit Working Group (2018) Twelve questions for the participatory modeling community. Earth's Future 6(8):1046-1057

Laska S, Wooddell G, Hagelman R, Gramling R, Farris MT (2005) At risk: the human, community and infrastructure resources of coastal Louisiana. J Coast Res 90-111

Landström C, Whatmore SJ, Lane SN, Odoni NA, Ward N, Bradley S (2011) Coproducing flood risk knowledge: redistributing expertise in critical 'participatory modelling'. Environ Plan A Econ Space 43(7):1617-1633

Lewis JA, Ernstson H (2017) Contesting the coast: ecosystems as infrastructure in the Mississippi River Delta. Prog Plan 129:1-30

Louisiana Coastal Protection and Restoration Authority (2012) Louisiana's comprehensive master plan for a sustainable coast. Louisiana Coastal Protection and Restoration Authority, Baton Rouge, p 188

Louisiana Coastal Protection and Restoration Authority (2017) Louisiana's comprehensive master plan for a sustainable coast. Louisiana Coastal Protection and Restoration Authority, Baton Rouge

Mavrommati G, Borsuk ME, Howarth RB (2017) A novel deliberative multicriteria evaluation approach to ecosystem service valuation. Ecol Soc 22(2)

Mendoza GA, Prabhu R (2005) Combining participatory modeling and multi-criteria analysis for community-based forest management. For Ecol Manag 207(1-2):145-156

Meselhe E, Baustian MM, Allison M (eds) (2015) Basin wide model development for the Louisiana coastal area mississippi river hydrodynamic and delta management study. The Water Institute of the Gulf, Baton Rouge (Funded by the Coastal Protection and Restoration Authority under Task Order 27.1)

Meselhe E, Wang Y, White E, Jung H, Baustian MM, Hemmerling S, Barra M, Bienn H (in press) Development of knowledge-based predictive tools to assess effectiveness of natural and nature-based solutions for coastal restoration and protection planning. J Hydraul Eng

Mitsch WJ, Gosselink JG (1986) Wetlands. Van Nostrand Reinhold Company, New York

Scavia D, Field JC, Boesch DF, Buddemeier RW, Burkett V, Cayan DR, Fogarty M, Harwell MA, Howarth RW, Mason C et al (2002) Climate change impacts on US coastal and marine ecosystems. Estuaries 25(2):149-164

Stave K (2010) Participatory system dynamics modeling for sustainable environmental management: observations from four cases. Sustainability 2(9):2762-2784

Steel D, Whyte KP (2012) Environmental justice, values, and scientific expertise. Kennedy Inst Ethics J 22(2):163-182

Travers A, Elrick C, Kay R, Vestergaard O (2012) Ecosystem-based adaptation guidance: Moving from principles to practice. United Nations Environment Programme: Nairobi, Kenya, 2015, 2071-1050

Turner RE (1997) Wetland loss in the northern Gulf of Mexico: multiple working hypotheses. Estuaries 20(1):1-13

Voinov A, Gaddis EJB (2008) Lessons for successful participatory watershed modeling: a perspective from modeling practitioners. Ecol Model 216(2):197-207

Voinov A, Jenni K, Gray S, Kolagani N, Glynn PD, Bommel P, Prell C, Zellner M, Paolisso M, Jordan R, Sterling E, Schmitt Olabisi L, Giabbanelli PJ, Sun Z, Le Page C, Elsawah S, BenDor TK, Hubacek K, Laursen BK, Jetter A, Basco-Carrera L, Singer A, Young L, Brunacini J, Smajgl A (2018) Tools and methods in participatory modeling: selecting the right tool for the job. Environ Model Softw 109:232-255

Whatmore SJ (2009) Mapping knowledge controversies: science, democracy and the redistribution of expertise. Prog Hum Geogr 33(5):587-598 
Publisher's Note Springer Nature remains neutral with regard to jurisdictional claims in published maps and institutional affiliations.

\section{Affiliations}

Scott A. Hemmerling ${ }^{1}{ }^{(1)} \cdot$ Monica Barra ${ }^{2} \cdot$ Harris C. Bienn ${ }^{1}$. Melissa M. Baustian ${ }^{1} \cdot$ Hoonshin Jung ${ }^{1} \cdot$ Ehab Meselhe $^{3} \cdot$ Yushi Wang $^{1} \cdot$ Eric Wh ite $^{1}$

1 The Water Institute of the Gulf, 1110 S. River Road, Baton Rouge, LA 70802, USA

2 Department of Anthropology, University of South Carolina, 701 Sumter Street, Columbia, SC 29208, USA

3 Department of River-Coastal Science and Engineering, Tulane University, 6823 St. Charles Avenue, New Orleans, LA 70118, USA 